\title{
Personalized Nutrition for Management of Micronutrient Deficiency-Literature Review in Non-bariatric Populations and Possible Utility in Bariatric Cohort
}

\author{
Shannon Galyean ${ }^{1}$ (D) $\cdot$ Dhanashree Sawant ${ }^{1} \cdot$ Andrew C. Shin ${ }^{1}$ \\ Received: 31 January 2020 / Revised: 01 June 2020 / Accepted: 04 June 2020 / Published online: 20 June 2020 \\ (C) The Author(s) 2020
}

\begin{abstract}
Background Bariatric surgery can effectively treat morbid obesity; however, micronutrient deficiencies are common despite recommendations for high-dose supplements. Genetic predisposition to deficiencies underscores necessary identification of highrisk candidates. Personalized nutrition (PN) can be a tool to manage these deficiencies.

Methods Medline, PubMed, and Google Scholar were searched. Articles involving genetic testing, micronutrient metabolism, and bariatric surgery were included.

Results Studies show associations between genetic variants and micronutrient metabolism. Research demonstrates genetic testing to be a predictor for outcomes among obesity and bariatric surgery populations. There is limited research in bariatric surgery and micronutrient genetic variants.

Conclusion Genotype-based PN is becoming feasible to provide an effective treatment of micronutrient deficiencies associated with bariatric surgery. The role of genomic technology in micronutrient recommendations needs further investigation.
\end{abstract}

Keywords Obesity $\cdot$ Gene $\cdot$ Polymorphism $\cdot$ Gene expression $\cdot$ Nutrients $\cdot$ Supplementation $\cdot$ Deficiency

\section{Background}

The prevalence of obesity is consistent with more than one third of adults having the disease of obesity [1]. Obesity is the focus for many public health efforts in the USA with one treatment option being bariatric surgery $[1,2]$. Achieving weight loss is a benefit from bariatric surgery; however, micronutrient deficiencies can occur [2]. Micronutrient deficiencies are associated with serious consequences due to the negative effects on metabolic and cellular signaling pathways. Possible causes of micronutrient deficiencies after bariatric surgery are decreased food intake, food intolerance, reduced gastric secretions, bypass of intestinal surface area for absorption, as well as failure to comply with recommended vitamin regimens [3, 4]. Multiple case series have reported postoperative, malabsorptive procedures to increase prevalence of iron deficiency to $20-49 \%$,

Shannon Galyean

shannon.galyean@ttu.edu

1 Department of Nutritional Sciences, Texas Tech University, 1301 Akron Ave, Lubbock, TX 79409, USA calcium and vitamin D deficiency 25-50\%, vitamin $\mathrm{B}_{12}$ deficiency about $33 \%$, and folate deficiency as high as $45 \%$ [3]. For malabsorptive procedures, patients are recommended to take at least double the recommended daily dose of a multivitamin plus mineral supplement and additional 1200-2400 mg calcium, $3000 \mathrm{IU}$ vitamin D to reach levels $>30 \mathrm{ng} / \mathrm{mL}$, and vitamin B12 as needed for normal levels [5]. In a cohort of adults who underwent bariatric surgery, $73 \%$ of the patients had at least one nutritional deficiency 5 years later even though they reported taking a dietary supplement [6]. However, there are some patients, up to $47 \%$, that may be non-responders to supplements even with compliance rates of about 86-93\% [7]. Indeed, individuals respond differently to dietary interventions. Genetic variation among individuals could be the root cause for varying responses to the same regimen and explains why some individuals respond better to a certain regimen than others in the same environmental conditions [8].

\section{Introduction}

Genetic testing can be a critical tool for health and medical diagnosis, treatment, and prevention. Predictive testing may 
be among the most useful tests regarding medical nutrition therapy (MNT). Genetics along with environment and behavior are the key to providing the best assessment, intervention, and tailored changes for an individual [9]. MNT should follow an appropriate paradigm that encompasses prediction (early diagnosis), prevention (intervention on healthy persons), and a tailored therapy for patients [9]. Identifying ways for early intervention may help develop strategies for preventing poor nutritional status and maximizing surgery-induced metabolic benefits later.

Sequencing of the human genome and identifying genenutrient interactions are the underlying concept of PN [10]. Nutrigenomics is the study of the effect of specific nutrients on gene expression [10], while nutrigenetics refers to the study of genetic variations of an individual that can provide some prediction to help prevent as well as contribute to personalized dietary management [11]. Both nutrigenomics and nutrigenetics may be a strategy to improve understanding of the gene-diet interaction and deliver individualized MNT to prevent chronic nutrition-related diseases [(10], [11)]. The usefulness and validity of this type of PN are in their infancy, although some studies have shown that individuals find dietary recommendations based on genetics more beneficial than general dietary advice [12]. A survey conducted by the publisher Nature showed that $27 \%$ of respondents who had their genomes analyzed changed their diet, lifestyle, or medication based on their genetic information [13]. However, another study reported that genetic testing led to no short-term changes in specific dietary or exercise behaviors [14]. Thus, increased understanding and awareness of these tests is required to effectively use them among public and healthcare providers [12].

Since many micronutrients control energy metabolism, their deficiencies can result in an array of symptoms, ranging from anemia to neurological dysfunction $[15,16]$. Additionally, subclinical micronutrient deficiency can lead to increased risks for coronary artery disease, infections, age-related macular degeneration, and oxidative damage [17, 18]. Therefore, measuring nutritional status in the context of pathophysiology is critical, but this is a major challenge because it is influenced by a number of factors including dietary consumption, physical/social stressors, and infections [19]. Furthermore, the impact of nutrition could vary among individuals and specific population subgroups based on their molecular and genetic make-up [19]. Studying this complex nutrient-gene relationship to understand the metabolic networks in context of health and disease should be a focus. It can provide information on potential biomarkers of nutritional status, disease progression, and response to interventions. This literature review aims to summarize data from studies of genes involved in micronutrient metabolism. Identifying these nutrient-gene pathways and their variants can help predict those at risk for deficiencies. This may recognize the need for increasing consumption of essential nutrients to intervene prior to bariatric surgery and develop strategies to prevent micronutrient deficiency postoperatively.

\section{Methods}

Due to the limited amount of literature published on micronutrient deficiencies, micronutrient genetic variants, and bariatric surgery, the authors conducted a narrative review. A comprehensive search of the literature from 1975 to 2020 was conducted to identify articles examining the association between genetic variants of micronutrient metabolic pathways and serum levels of micronutrients. Searches were conducted in databases that contain research related to health and metabolic outcomes, including PubMed, Medline, and Google Scholar. The search terms that were used included genetic variants, micronutrient metabolism, treatment of genetic defects of micronutrients, precision nutrition, nutrigenomics, and bariatric surgery. Additionally, review articles produced through the database searches were examined for further articles that fit within the inclusion criteria and thus were included in the results.

\section{Inclusion/Exclusion Criteria}

Criteria for inclusion in the review were [1] peer-reviewed articles, [2] articles that included empirical data, [3] articles published or available in English, [4] articles that included people with low micronutrient levels, [5] articles that included people that had micronutrient genetic variants, [6] supplementation/treatment regimens for people with genetic variants and low micronutrient levels, and [7] articles that included genetic testing among obesity and bariatric surgery populations and outcomes that were examined. Only two articles involving micronutrient genetic variants among bariatric surgery patients were found. Due to this limitation, studies involving non-surgical patients and micronutrient genetic variants were included. Other studies involving genetic testing and bariatric surgery were included to demonstrate its potential as a tool for this patient population. There were also limitations on studies involving treatment and supplementation according to genetic variants. Ideally, inclusion criteria would comprise of studies with a high number of participants, a control group, and that used similar measures and procedures across studies for comparison; however, using the search methods and criteria described above, 80 articles met the inclusion criteria. All the authors confirmed that the articles met the inclusion criteria and were appropriate for the review. The articles that met the inclusion criteria focused on micronutrient 
genetic variants and genetic testing in diverse populations shifting to describe the findings.

\section{Results}

Of the 80 articles included, 2 were published between 1975 and 1990, 5 were published between 1991 and 2000, 25 were published between 2001 and 2010, and 48 were published between 2011 and 2020. Twenty-two of these studies took place in the USA, and the rest were conducted in other countries. The articles were divided into four categories which are used to organize the results: [1] micronutrient deficiencies prevalent among bariatric surgery patients (19 articles), [2] micronutrient genetic variants prevalence among different populations (29 articles), [3] clinical trials involving supplementation for micronutrient genetic variants (26 articles), and [4] genetic testing studies in persons with obesity and bariatric surgery populations ( 6 articles).

\section{Genetic Variants and Their Effect on Vitamin and Mineral Pathways and Response to Supplementation}

Genetic variations in specific genes among vitamin and mineral metabolic pathways are associated with altered nutrient homeostasis and adverse health outcomes [19]. SNPs are the most common type of genetic variations among people [20]. In the human genome, SNPs may occur at every 1000 nucleotides, which means that a person may have 4-5 million SNPs [20]. SNPs are known to impact micronutrient status or chronic diseases related to micronutrient metabolism [19, 21-23]. The ability to identify a person having genetic variants involved in vitamin and mineral metabolism may reduce the chance of developing micronutrient deficiencies that can lead to various diseases [19]. GWAS have shown that several genetic variants associated with vitamin metabolism can affect circulating vitamin levels, which could lead to abnormal vitamin function [24]. Most GWAS have been conducted among healthy, Caucasian populations, which is a limitation in this research [24]. Table 1 demonstrates recent studies that associate genetic variants and micronutrient metabolism.

\section{Vitamin D}

Vitamin D is essential for many functions of the body. Deficiency of vitamin D is associated with many cancers, autoimmune disorders, and cardiovascular disease as well as significantly affects musculoskeletal function [39-41]. Obesity has been identified as a risk factor of vitamin D deficiency, and those seeking bariatric surgery for obesity treatment have an additional risk for low vitamin D levels post-op [39]. One study showed that $57.4 \%$ of patients seeking bariatric surgery were vitamin D-deficient preoperatively [39]. In 51 observational studies assessing vitamin D status in patients undergoing bariatric surgery, the mean $(25(\mathrm{OH}) \mathrm{D})$ level was less than $30 \mathrm{ng} / \mathrm{ml}$ (which is the minimum recommended level for optimal long-term health), before and after bariatric surgery, despite various vitamin $\mathrm{D}$ supplementation regimens [42]. Another review of 30 studies showed vitamin D deficiency prevalence to range from 13 to $90 \%$ preoperatively which was maintained after surgery [43].

The heritability of vitamin D status is estimated to be $30 \%$ and common variants group-specific component $(G C)$ (also known as vitamin D-binding protein); 7-dehydrocholesterol reductase (DHCR7) and CYP2R1 (involved in 25-hydroxylase production) are associated with fasting plasma $25(\mathrm{OH}) \mathrm{D}$ concentrations [25, 44, 45]. Nissen and colleagues have shown that 7 prominent variants in CYP2R1 and GC genes were significantly associated with low serum $25(\mathrm{OH})$ D concentrations [26]. People who have these common genetic variations could be treated on a more individualized basis to correct deficiencies that occur.

One randomized controlled trial looked at older Australians randomly assigned to monthly doses of 30,000 IU or $60,000 \mathrm{IU}$ vitamin $\mathrm{D}_{3}$ for 12 months and found that genetic variability is associated with response to supplementation, perhaps suggesting that some people might need a higher dose to reach optimal 25(OH) D levels [46]. Another study investigated 41 candidate single nucleotide polymorphisms (SNPs) in vitamin $\mathrm{D}$ and calcium pathway genes among healthy nonHispanic white participants and stated that the increase in $[25(\mathrm{OH}) \mathrm{D}]$ attributable to vitamin D3 supplementation may vary according to common genetic differences in CYP2R1, 24-hydroxylase (CYP24A1), and vitamin D receptor (VDR) genes [27]. There is evidence from three randomized controlled trials that indicate a strong association between genetic polymorphisms and levels of serum $25(\mathrm{OH}) \mathrm{D}$ in response to 40,000 IU vitamin D/week given for 6 months [47]. However, there is a wide variation in the response of blood $25(\mathrm{OH}) \mathrm{D}$ to vitamin D supplementation that is associated with genetic variants in vitamin D metabolism [25].

\section{Vitamin B12}

Vitamin B12 is a coenzyme, cofactor, and essential component in vitamin B complex. It is essential for cardiac health [48] and cognitive function [49, 50]. Deficiency of vitamin B12 can lead to deleterious consequences including macrocytic anemia, neuropsychiatric symptoms [51], cardiovascular diseases [52, 53], and onset of different forms of cancer [54, 55]. The most common cause of vitamin B12 deficiency is loss of intrinsic factor (IF) as absorption depends on it [56]. People who have bariatric surgery, short gut syndrome, long-term vegetarian, or vegan diets can potentially develop vitamin B12 deficiency [56]. While vitamin B12 level can be normal at baseline, it is often found to be lower in individuals after bariatric surgery $[57,58]$. 
Table 1 Relevance of genetic variants associated with micronutrient metabolism

\begin{tabular}{|c|c|c|c|}
\hline Micronutrients & $\begin{array}{l}\text { Genes identified } \\
\text { with micronutrients }\end{array}$ & Relevance in micronutrient status & Reference \\
\hline Vitamin D & $\begin{array}{l}\text { 1. GC } \\
\text { 2. CYP2R1 } \\
\text { 3. DHCR7 } \\
\text { 4. CYP24A } \\
\text { 5. VDR }\end{array}$ & $\begin{array}{l}\text { 1. GC gene encodes Vitamin D Binding Protein (DBP) which is a glycosylated } \\
\text { alpha-globulin that transports vitamin D metabolites from gut and skin } \\
\text { to target end-organs. } \\
\text { 2. CYP2R1 gene encodes } 25 \text {-hydroxylase, which converts Vitamin D to } 25(\mathrm{OH}) \mathrm{D} \text {. } \\
\text { 3. DHCR7 gene provides instructions for making 7-dehydrocholesterol reductase, } \\
\text { an enzyme involved in the final step of cholesterol production. } \\
\text { 4. CYP24A gene provides instructions for making } 24 \text {-hydroxylase, an enzyme } \\
\text { that controls the amount of active vitamin D in the body. } \\
\text { 5. VDR gene provides instructions for making vitamin D receptor (VDR) protein, } \\
\text { which allows the body to respond appropriately to vitamin D } \\
\text { >A variation in these genes may impact body vitamin D levels. }\end{array}$ & {$[25-28]$} \\
\hline $\mathrm{B} 12$ & $\begin{array}{l}\text { 1. FUT2 } \\
\text { 2. CUBN } \\
\text { 3. TCN1 } \\
\text { 4. MTRR } \\
\text { 5. TCN2 } \\
\text { 6. MTR } \\
\text { 7. MMAA } \\
\text { 8. MMACHC }\end{array}$ & $\begin{array}{l}\text { 1. FUT2 gene encodes for fucosyltransferase } 2 \text { gene and is involved in Vit B12 } \\
\text { absorption and transport. } \\
\text { 2. CUBN gene provides instructions for making cubilin protein which is involved } \\
\text { in the uptake of vitamin B12. } \\
\text { 3. TCN1 gene encodes B12-binding protein family which facilitates the transport } \\
\text { of cobalamin into cells. } \\
\text { 4. MTRR gene is responsible for maintaining adequate levels of activated vitamin } \\
\text { B12, which maintains methionine synthase enzyme in its active state. } \\
\text { 5. TCN2 provides instructions for making transcobalamin. } \\
\text { 6. MTR gene provides instructions for making methionine synthase enzyme which } \\
\text { needs B12 and is involved in the formation of the amino acid methionine } \\
\text { 7. The protein encoded by MMAA gene is involved in the translocation of } \\
\text { cobalamin into the mitochondrion. } \\
\text { 8. It is postulated that the protein encoded by MMACHC gene may have a role in } \\
\text { the binding and intracellular trafficking of cobalamin. } \\
\text { SNP related to these genes can lead to insufficient B12 levels in the body. }\end{array}$ & {$[28-31]$} \\
\hline Folic acid & 1.MTHFR & $\begin{array}{l}\text { 1. MTHFR gene produces Methylenetetrahydrofolate reductase (MTHFR) } \\
\text { which is a vital enzyme for the folate pathway. } \\
\text { >SNP related to this gene may be an important marker to identify people at risk } \\
\text { for lower plasma folate concentrations, changes in folate form distribution, } \\
\text { and elevated plasma homocysteine concentrations. }\end{array}$ & {$[28,32-34]$} \\
\hline Thiamine & $\begin{array}{l}\text { 1.SLC19A2 } \\
\text { 2. SLC19A3 } \\
\text { 3. SLC35F3 }\end{array}$ & $\begin{array}{l}\text { SLC19A2, SLC19A3 and SLC35F3 genes code for thiamine transporter } \\
\text { protein which allow thiamine to move into the cells. } \\
>\text { Mutations in these gene can cause thiamine deficiency leading to thiamine } \\
\text { responsive megaloblastic anemia. }\end{array}$ & {$[28,35,36]$} \\
\hline Iron & $\begin{array}{l}\text { 1.TMPRSS6 } \\
\text { 2.TFR2 } \\
\text { 3.TF } \\
\text { 4. HFE }\end{array}$ & $\begin{array}{l}\text { 1. TMPRSS6 gene codes for the protein matriptase- } 2 \text { which helps in regulation } \\
\text { of iron balance. } \\
\text { 2. TFR2 gene codes for TFR } 2 \text { protein which facilitates entry of iron into the cells. } \\
\text { 3. TF gene codes for protein transferrin which is a transport protein for iron in the body. } \\
\text { 4. HFE gene provides instruction for production of HFE protein which } \\
\text { determines iron absorption from diet and iron release from body stores. } \\
\text { A variation in these genes together has an impact on the risk of insufficient iron } \\
\text { levels in the body. }\end{array}$ & {$[28,37,38]$} \\
\hline
\end{tabular}

Nutritional parameters were compared preoperatively and at similar periods postoperatively among patients undergoing malabsorptive procedures [59]. Vitamin B12 abnormalities prior to surgery ranged from $3.2-8.3 \%$ to $24-25 \%$ at 1 year postop [59]. In a study of gastric bypass surgery subjects, vitamin B12 deficiency was observed in $33.3 \%$ at 2 years and in $27.2 \%$ at 3 years postoperatively [60].

Genetic variants may impact the proteins involved in vitamin B12 absorption, cellular uptake, and intracellular metabolism [61-63]. Genetic influence for B12 levels is estimated to be 59\% in a study using monozygotic and dizygotic twins [64] and $27 \%$ in another study among Icelandic sibling pairs [65]. Variants of the transcobalamin 1 (TCN1) gene (vitamin B12 binding protein, transcobalamin I (TCI)) have been associated with circulating B12 concentrations [29, 66]. Genetic variants of fucosyltransferase 2 (FUT2 gene) that codes for an enzyme in the vitamin B12 pathway are associated with B12 levels [29]. Transcobalamin 2 (TCN2) gene is responsible for making a B12-binding protein called transcobolamin II (TC) that carries B12 from the intestine to blood and liver. Although TC represents approximately $10-20 \%$ of circulating $\mathrm{B} 12$, the most common variant of this gene among Caucasian 
populations has been associated with B12 levels [29]. In a study among Irish men, having this SNP and homozygous CC genotype had lower vitamin B12 levels than those with GG genotype [67]. This demonstrates that different genotypes of transcobalamin impact the distribution of vitamin B12 and shows an association between this genetic variant and B12 levels [67].

Vitamin B12 along with folate influences one-carbon metabolism. Cubulin (CUBN) is the intestinal (IF) and polymorphisms of this gene have been associated with chronic diseases in individuals with low B12 status [29]. A study involving a Canadian population found that many SNPs in genes related to folate, B12, and homocysteine metabolismCUBN, TCN1, TCN2, methylenetetrahydrofolate reductase (MTHFR), MUT (methylmalonyl coenzyme A mutase), and FUT2 - are possibly correlated with B vitamin-related diseases [30]. Genetic polymorphisms of MTHFR, MTR, MTRR, MMAA (methylmalonic aciduria (cobalamin deficiency) cb1A type), MMACHC (methylmalonic aciduria and homocystinuria, cblC type), and MUT have been analyzed. This research has failed to show an association between MTHFR gene polymorphisms and B12 concentrations [29]. However, a study using a classic twin model found that common gene variants-MMAA, MMACHC, MTRR, and MUT-were significantly associated with B12 levels and could explain the variation in B12 levels, which might facilitate the prevention and treatment of B12 insufficiency/ deficiency in individuals at a higher risk of associated diseases [68]. A cross sectional study looking at 56 SNPs of the B12 pathway among an older female population and found TCN2 to be significantly associated with elevated serum methylmalonic acid (MMA) levels, a marker for available B12 [69]. When using MMA levels as a marker for B12, it is suggested that TCN2 gene variants may lead to decreased vitamin B12 availability [69]. This review spotlights the complex nature of nutrigenomics and vitamin B12. Identifying these gene variants among people having bariatric surgery could contribute to a more personalized nutrition plan.

\section{Folate}

Folate plays a role in one-carbon metabolism, methylation and DNA synthesis, and methionine regeneration [70-72]. Folate deficiency is associated with elevated homocysteine, cardiovascular diseases, neural tube defects, cleft lip and palate, late pregnancy complications, neurodegenerative and psychiatric disorders [73-75]. Elevated homocysteine levels are a risk marker for dementia, Alzheimer's disease, bone fractures, cancers, and cardiovascular diseases [76-78]. Many studies show folate deficiency to be low due to food fortification in America [39, 79-81]. Although preoperative deficiencies are not alarming, prevalence of folate deficiency and elevated homocysteine have shown to persist or worsen after bariatric surgery despite supplementation $[82,83]$. The prevalence of abnormalities 1 year after gastric bypass were higher compared to preoperative levels in 232 patients with elevated homocysteine as high as $29 \%$ and low RBC folate in $12 \%$ of 149 postoperative subjects [82]. Another study found similar results among patients undergoing bariatric surgery with $13 \%$ having folate deficiency postoperatively [84].

Several studies have shown an association between SNPs related to folate metabolism, folate deficiency, and elevated homocysteine [70]. A common genetic variant in MTHFR is known to influence blood folate and prevalent in $10 \%$ of the population worldwide $[85,86]$. Steluti and colleagues studied polymorphism frequencies and differences in homocysteine concentrations even in the presence of folic acid fortification and found that homocysteine levels increased in those carrying genetic variants in folate metabolism, specifically in the MTHFR gene [87]. The prevalence of variant MTHFR TT has been found in 25\% of Americans of Hispanic origin, 10-15\% among white Americans, and only $0-1 \%$ for African Americans [77, 87-89]. A review examining the nutritional deficiencies, bariatric surgery, and serum homocysteine levels found that the mutations of the MTHFR gene can be one of the reasons for persistent elevated serum homocysteine after surgery despite supplementation with B-group vitamins [76]. Knowing the presence of genetic variants of folate metabolism would provide a critical personalized care to those that might benefit from the methylated form of folic acid to prevent elevated homocysteine levels [76].

\section{Thiamine}

Thiamine is essential for glucose, amino acid, and energy metabolisms [90-92]. Deficiency of thiamine can cause complications including cardiovascular and neurological diseases, including Wernicke-Korsakoff syndrome [90, 93]. Preoperative thiamine deficiency is prevalent in about $29 \%$ of patients undergoing bariatric surgery [57]. Studies have found that preexisting thiamine deficiency can be present in $15.5 \%$ and as high as $47 \%$ of patients; however, race plays a role showing Hispanic patients with the highest level of prevalence followed by African Americans (31\%) and Caucasians (7\%) $[57,79,94]$. Similarly, a retrospective study showed $33.6 \%$ of patients having thiamine deficiency pre-operatively, suggesting that people with obesity, especially those with many weight loss attempts, may have different needs to maintain adequate thiamine levels [95].

Mutations in thiamine transporter genes, SLC19A2 and SLC19A3, have been observed in cases of thiamine deficiency due to decreased absorption of thiamine that leads to neurological dysfunction [91]. SLC35F3 is another thiamine transporter gene that plays a role in cardiac health and blood pressure. Genetic variants have been associated with thiamine deficiency as well as hypertension [35]. Prevalence of 
mutations in these genes is largely unaccounted for despite recent advances in GWA studies. However, studies show that thiamine deficiency and cardiac dysfunction associated with these genetic variants are alleviated with thiamine supplementation [96-99]. Literature reviews have shown that treatment for thiamine deficiency vary according to the genetic defect of thiamine metabolism and that supplementation results in adequate thiamine levels and improved clinical outcomes [100, 101]. The best responses to thiamine therapy were associated with early referral for genetic testing and early initiation of thiamine treatment. This evidence demonstrates that early diagnosis of these mutations can be beneficial. It may also implicate the hereditability of thiamine deficiency and that therapeutic doses of thiamine vary according to the genetic defect.

\section{Iron}

Iron is essential for metabolic processes like oxygen transport, deoxyribonucleic acid (DNA) synthesis, electron transport, as well as cellular functions can affect one's well-being [102]. In individuals with obesity, the chronic inflammatory state related to obesity might be a possible risk factor for iron deficiency, which is also called the anemia of inflammation [57, 103-105]. Studies have shown that the prevalence of iron deficiency in adults with obesity is remarkable, and a decrease in serum iron and transferrin saturation levels is inversely associated with an increase in body mass index [103, 106-108]. A study involving bariatric surgery candidates showed $86.2 \%$ of females and $80 \%$ of males to be iron deficient prior to surgery [109]. A retrospective analysis of patients undergoing RYGB surgery showed that $43.9 \%$ were iron-deficient pre-operatively, which may be associated with higher complication rates as well as worsening of iron deficiency after surgery $[57,110,111]$. These findings reaffirm the need to assess and possibly intervene to manage deficiency in bariatric surgery candidates preoperatively.

Considering the results of several GWAS, there is strong evidence of genetic regulation of iron metabolism, and mutations in transmembrane serine protease 6 (TMPRSS6) gene that encodes for an enzyme that regulates hepcidin involved in iron homeostasis, iron carrier transferrin (TF), and transferrin receptor-2 (TFR2) genes have been associated with iron deficiency [112]. A GWAS concluded that identifying mutations in the TMPRSS6 gene has broad applications in understanding clinical disorders of iron metabolism, and polymorphisms in TMPRSS6 gene may contribute to iron deficiency anemia (IDA) in individuals even in absence of other predisposing factors for IDA [112]. Studies have shown a common TMPRSS6 gene variant to be prevalent in $45 \%$ of the individuals without iron deficiency and clinically relevant inflammatory conditions [104] and $36.5-41.7 \%$ in a group of nonpregnant women [113]. TF and human hemochromatosis (HFE) genes are involved in genetic regulation of maintenance of iron homeostasis [37]. Mutations in the HFE gene can lead to hereditary hemochromatosis, an iron overload disorder [114]. These factors should be considered to possibly affect iron absorption and thus response to treatment.

TMPRSS6 mutations have been associated with refractoriness to oral iron and studies confirm the role of TMPRSS6 in predicting oral iron response $[114,115]$. One study evaluated subjects with persistent IDA to poorly respond to oral iron, indicating that TMPRSS6 polymorphisms are more frequent in subjects with persistent IDA [115]. Identifying mutations of these iron-related genes can help with providing personalized iron supplementation for a common deficiency post bariatric surgery.

\section{Association Between Genetic Defects and Micronutrient Supplementation}

The vitamin and mineral supplementation studies that focus on treating genetic disorders are mainly case studies. Supplementation studies for vitamin D-related genetic variants have been conducted in populations that are overweight and have obesity. Limited data is available on micronutrient supplementation according to genetic variants in bariatric surgery populations. Table 2 shows studies involving micronutrient supplementation according to genetic defect in diverse populations.

\section{Bariatric Surgery, Genetic Testing, and Gene Expression Profiles}

Genetic expression patterns can be a predictive tool for responsiveness to nutritional treatments. Some studies have indicated that surgery-induced weight loss was associated with remodeling of the epigenome that helps regulate metabolic gene expression $[125,126]$. One study found that 1366 genes were differentially expressed after bariatric surgery and subsequent weight loss, which are associated with gene transcription and energy metabolism [127]. Knowing the impact of bariatric surgery on the vitamin/mineral metabolic pathways can lead to successful prevention and treatment of micronutrient deficiencies. A study that specifically assessed the mRNA of genes within B12 degradation pathway after gastric bypass found that the intestine reprogrammed its genetic phenotype to compensate for the changes in B12 metabolism. The authors also found decreased expression of TCN1 but an increased production of CUBN, which reflects adaptive genetic reprogramming [128]. However, research on the role of vitamin metabolism genes and their adaptation after bariatric surgery is scarce. We do know that healthy individuals and people with obesity have different gene expression profiles and bariatric surgery further modifies the epigenome [129, 130]. Genetic testing is a useful tool for applying personalized medicine in bariatric surgery patients as demonstrated by 
Table 2 Supplementation trials according micronutrient defect

Reference Micronutrient $\begin{aligned} & \text { Defective or Dosage and monitoring } \\ & \text { mutated } \\ & \text { gene }\end{aligned}$

[116] Thiamine SLC19A2 $75 \mathrm{mg}$ thiamine/day

Vitamin D GC Folic acid (FA)

$\begin{array}{lcc}\text { Vitamin B12 } & \begin{array}{c}\text { MTHFR } \\ 677 \mathrm{C} \rightarrow \mathrm{T} \\ \text { genotype }\end{array} & \begin{array}{l}\text { One vitamin tablet consisting of } 2 \mathrm{mg} \text { of } \\ \text { folic acid, } 25 \mathrm{mg} \text { vitamin B6, and }\end{array} \\ & \begin{array}{l}400 \mu \mathrm{g} \text { of vitamin B12 daily for } \\ 6 \text { months }\end{array}\end{array}$

\section{SLC19A3}

$100 \mathrm{mg}$ thiamine $2 \times /$ day along with $10 \mathrm{mg}$ biotin $2 \times$ /day for 5 months

$500 \mathrm{mg}$ thiamine/day
Case study of 1 female patient

Case study of 1 female patient

2 patients with homozygous TPKImutation-

50,000 IU vitamin D3 per week for 8 weeks, followed by daily maintenance of 1000 IU vitamin D3 for 4 months

CYP2R1, Vitamin D3 (1000 IU/day) and/or calcium CYP24- carbonate $(1200 \mathrm{mg} /$ day elemental A1, VDR calcium)

MTHFR

Each treatment taken once daily for 8 weeks.

1. Enalapril only (10 mg, control group)

2. Enalapril-FA tablet (10 mg enalapril combined with $0.4 \mathrm{mg}$ of FA)

3. Enalapril-FA tablet (10 mg enalapril combined with $0.8 \mathrm{mg}$ of FA)

MTHFR 3 random dietary interventions (4 months $677 \mathrm{C} \rightarrow \quad$ each):

$\mathrm{T}$ 1. Exclusion diet (avoidance of genotype FA-fortified foods)

2. Folate-rich diet (folate-rich foods to achieve $400 \mathrm{mcg}$ folate/d)

3. Supplement (exclusion diet plus a folate supplement of $400 \mathrm{mcg} /$ day)
52 patients with migraine with aura.

\section{4 participants with vitamin D deficiency}

\section{7 healthy participants}

480 subjects with mild or moderate essential hypertension

126 healthy subjects ( 42 TT, $42 \mathrm{CT}$, and $42 \mathrm{CC}$ genotypes)
HFE,

TMPRS-
Iron supplementation with autrin capsules (ferrous fumarate; $98.6 \mathrm{mg}$ elemental iron) once a day for 20 weeks from the time of diagnosis
181 pregnant women with anemia
Patients with this defect present with diabetes mellitus, megaloblastic anemia, and sensorineural deafness. Thiamine supplementation improved blood glucose and insulin requirements decreased.

This genetic defect causes ophthalmoplegia, ataxia and confusion. Oral biotin and thiamine improved the symptoms dramatically the next day.

Early thiamine supplementation prevented encephalopathic episodes and improved developmental progression. Evidence suggests that thiamine supplementation may rescue TPK enzyme activity.

Carriers of GC mutation showed the lowest baseline 25(OH)D levels and lowest response to vitamin $\mathrm{D}$ supplementation. Mutations in GC gene can predict response to vitamin D supplementation.

The increase in $[25(\mathrm{OH}) \mathrm{D}]$ attributable to vitamin D3 supplementation may vary according to common genetic differences in CYP2R1, CYP24A1, and VDR genes.

MTHFR mutation can affect homocysteine concentration at baseline and post-FA treatment as well as can modify therapeutic responses to various dosages of FA supplementation.

The TT homozygotes tended to have low plasma folate and high plasma homocysteine levels. Folate intervention on plasma folate was observed across genotypes. However, the TT homozygotes required higher supplement intervention to achieve similar effects observed in other genotypes suggesting a need for supplementation with at least 400-600 $\mathrm{mcg}$ /day for individuals with the TT genotype.

Vitamin supplementation lowered homocysteine and reduced migraine disability in a subgroup of patients. In this patient group the treatment effect on both homocysteine levels and migraine disability was associated with MTHFR C677T genotype; carriers of the $\mathrm{C}$ allele experienced a greater response compared to TT genotypes concluding that TT genotypes require a larger dosage of vitamins to exhibit the same effect as $\mathrm{C}$ alleles.

The HFE variant had a positive effect with significant improvement in hemoglobin, iron and ferritin. This shows an association of genetic variants and iron absorption and thus response to treatment. The TMPRSS6 
Table 2 (continued)

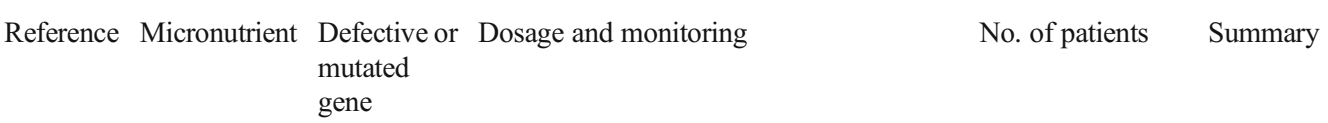

TMPRSS6 Intravenous iron gluconate

$(1.3 \mathrm{mg} / \mathrm{kg} /$ day $)$ for 5 days as first

course and same dose was repeated after

5 months

Followed by different supplementation

therapy in which the patient received

liposomal oral iron at a dose of

$10 \mathrm{mg} /$ day for 3 months mutation was significantly associated with higher serum iron and hemoglobin. The presence of variants in STEAP3, TMPRSS6, SLC11A2, SLC40A1, HAMP and $\mathrm{TF}$ genes indicate a probable genetic association with iron status.

Case study of 1 A comprehensive assessment that includes female patient sequence analysis of TMPRSS6 can help to confirm the genotype-phenotype association of genes involved in iron metabolism and may also be useful for predicting the patient's response to iron treatment.
Bandstein et al. that showed presurgery vitamin D levels may impact the size of genotype effects of FTO rs9939609 on weight loss among gastric bypass surgery patients [131]. Nutritional genomics may provide the path for precise nutrition recommendations to provide high-risk individuals with personalized treatment and to prevent micronutrient deficiencies.

\section{Discussion}

From the review, it is evident that the deficiencies of the studied micronutrients are influenced by genetic mutations. Postbariatric surgery, patients frequently have these deficiencies and knowledge of these mutations may have bearing on its management. Additional research is needed to establish this association. This review confirmed the scarcity of research that has been conducted in the area of bariatric surgery and micronutrient genetic variants, with only two articles being found in this search. This limitation should be considered when interpreting the findings in this discussion. Furthermore, the treatment regimen for those who have micronutrient genetic variants and undergoing bariatric surgery should be an area of future research.

Personalized dietary and supplement advice derived from genetic testing should be based on appropriately designed studies. Utility of data from GWAS in providing dietary advice is limited because it is not known what diet and supplement intakes are required to prevent and treat the deficiencies that might be caused by micronutrient genetic variants. Identifying how a genetic variant modifies the response to supplementation on the micronutrient status and possibly identify responders and non- responders will be required to understand this population and area of research. Genotype along with micronutrient blood levels would be the initial step in applying PN among bariatric surgery patients. Genetic marker is only one factor that influences improvements related to micronutrient status [132].

Future work should focus on genotyping for multiple variants in the micronutrient metabolic pathways and their additive and interactive effects to get a complete understanding of the influence of genetic factors on micronutrient metabolism. Then, utilizing genomic technology to understand this influence on the responses to micronutrient supplementation is also important. This would involve micronutrient status, genetic variations, and genetic interactions within metabolic pathways involving the micronutrient, its molecular targets, and environmental stressors [133].

Furthermore, studies should focus to understand the role of the gut microbiome and its influence on metabolism and physiology. The human gut microbiota (which has its own genome) can modulate signaling pathways and regulate gene expression [134]. Diet, lifestyle, medications, and environmental exposure can increase inflammation within the gut, causing dysbiosis, which can contribute to chronic diseases and other illnesses [135]. Interestingly, gut microbial contribution to vitamin metabolism has been recognized in wholegenome metagenomic studies, suggesting microbe-mediated vitamin metabolism [136, 137]. Pre- and probiotics as well as diet can alter the gut microbiome in a manner that improves human health [138]. Investigating how the gut microbes can positively influence vitamin metabolism is warranted.

Techniques used for genetic testing will determine the cost. Methods being used in healthcare and research to identify genetic variations are known as next-generation sequencing 
(NGS) [28]. Sequencing costs have rapidly decreased, which has increased NGS applications in the clinical setting. There are 3 NGS approaches used: targeted gene panels (TGP), whole-exome sequencing (WES), and whole-genome sequencing (WGS) [139]. WGS implies the determination of the sequence of the entire genome of an individual; WES is a component of the genome; and TGP analyze specific mutations in a given set of genes or gene regions [140]. Per sample costs of diagnostic NGS applications, that include the total cost (in euros) of processing and analysis are estimated at $€ 333$ (TGP), €792 (WES), and €1669 (WGS) [139]. Another study showed cost analysis for cancer diagnosis using NGS. From the pre-analytical phase to delivery of results, cost per patient for TGP ranged from $€ 376$ to $€ 968$ [141]. Costs for NGS have declined and will continue to decline with innovations in genome-sequencing technologies and strategies [142]. In the area of bariatric surgery research, TGP could be utilized with the specific genes involved in micronutrient metabolic pathways, thus facilitating a more cost-effective and easy-tointerpret analysis.

Concerns and limitations involved in genetic testing include [1] the rapid growth of direct-to-consumer (DTC) genetic testing services with non-evidenced based testing, [2] potential ethical dilemmas, and [3] applications to the broader community [143]. Clinicians will be critical in providing genetic counseling regarding health decisions based on genomic information [144]. Many issues must be addressed prior to genetic testing such as informed consent, sample and data storage, return of results, and privacy and confidentiality to minimize these risks that can be introduced with such testing [145]. As mentioned previously, the majority of GWAS are conducted among Caucasian/European subjects. However, it is difficult to extrapolate from these studies to other populations. Sex differences also must be considered to improve the application of genetic tests to the broader community [143]. Addressing these areas and concerns are critical to implement genome sequencing in clinical practice. This type of analysis is likely to be cost-effective, especially in specific populations such as patients with bariatric surgery.

\section{Conclusion}

PN is the delivery of dietary advice at an individual level and future work should verify if this targeted nutrition can change behaviors and have an impact on health outcomes. Dietitians currently provide PN advice based on diet and phenotype; however, genotype-based PN advice is not so readily available. One review, involving a variety of populations such as patients with a history of weight loss failures, people with obesity, as well as healthy men and women of various ages, examined the evidence for genotype-based personalized information on motivating behavioral change, and factors which may affect the impact of genotype-based personalized advice [146]. The researchers reported that PN advice resulted in greater dietary changes compared with general healthy eating advice [146]. Analyzing biochemical markers for vitamins/ minerals as well as defining a person's "nutrigenomic profile" for those undergoing bariatric surgery will open the door to implement more personalized recommendations for micronutrient supplementation.

\section{Compliance with Ethical Standards}

Conflict of Interest The authors declare that they have no conflicts of interest.

Ethical Approval For this type of study, ethical approval and informed consent do not apply as it is a narrative review.

Open Access This article is licensed under a Creative Commons Attribution 4.0 International License, which permits use, sharing, adaptation, distribution and reproduction in any medium or format, as long as you give appropriate credit to the original author(s) and the source, provide a link to the Creative Commons licence, and indicate if changes were made. The images or other third party material in this article are included in the article's Creative Commons licence, unless indicated otherwise in a credit line to the material. If material is not included in the article's Creative Commons licence and your intended use is not permitted by statutory regulation or exceeds the permitted use, you will need to obtain permission directly from the copyright holder. To view a copy of this licence, visit http://creativecommons.org/licenses/by/4.0/.

\section{References}

1. Ogden CL, Carroll MD, Kit BK, et al. Prevalence of childhood and adult obesity in the United States, 2011-2012. JAMA. 2014;311(8):806-14. https://doi.org/10.1001/jama.2014.732.

2. Bloomberg RD, Fleishman A, Nalle JE, et al. Nutritional deficiencies following bariatric surgery: what have we learned? Obes Surg. 2005;15(2):145-54. https://doi.org/10.1381/ 0960892053268264.

3. Sawaya RA, Jaffe J, Friedenberg L, et al. Vitamin, mineral, and drug absorption following bariatric surgery. Curr Drug Metab. 2012;13(9):1345-55.

4. Ahmad DS, Esmadi M, Hammad H. Malnutrition secondary to non-compliance with vitamin and mineral supplements after gastric bypass surgery: What can we do about it? Am J Case Rep. 2012;13:209-13. https://doi.org/10.12659/AJCR.883335.

5. Mechanick JI, Apovian C, Brethauer S, et al. Clinical practice guidelines for the perioperative nutrition, metabolic, and nonsurgical support of patients undergoing bariatric procedures - 2019 update: cosponsored by American Association of Clinical Endocrinologists/American College of Endocrinology, the Obesity Society, American Society for Metabolic \& Bariatric Surgery, Obesity Medicine Association, and American Society of Anesthesiologists - Executive Summary. Endocr Pract. 2019;25(12):1346-59. https://doi.org/10.4158/GL-2019-0406.

6. Lombardo M, Franchi A, Padua E, et al. Potential nutritional deficiencies in obese subjects 5 years after bariatric surgery. Bariatric Surgical Practice and Patient Care. 2019;14(3):125-30.

7. Mahlay NF, Verka LG, Thomsen K, et al. Vitamin D status before Roux-en-Y and efficacy of prophylactic and therapeutic doses of 
vitamin D in patients after Roux-en-Y gastric bypass surgery. Obes Surg. 2009;19(5):590-4. https://doi.org/10.1007/s11695008-9698-1.

8. Ferguson LR, De Caterina R, Görman U, et al. Guide and position of the International Society of Nutrigenetics/Nutrigenomics on personalised nutrition: part 1 - fields of precision nutrition. $\mathrm{J}$ Nutrigenet Nutrigenomics. 2016;9(1):12-27. https://doi.org/10. $1159 / 000445350$

9. Trovato GM. Behavior, nutrition and lifestyle in a comprehensive health and disease paradigm: skills and knowledge for a predictive, preventive and personalized medicine. EPMA J. 2012;3(1):8. https://doi.org/10.1007/s13167-012-0141-2.

10. Fallaize R, Macready AL, Butler LT, et al. An insight into the public acceptance of nutrigenomic-based personalised nutrition. Nutr Res Rev. 2013;26(1):39-48. https://doi.org/10.1017/ S0954422413000024.

11. Crovesy L, Rosado EL. Interaction between genes involved in energy intake regulation and diet in obesity. Nutrition. 2019;6768:110547. https://doi.org/10.1016/j.nut.2019.06.027.

12. Nielsen DE, El-Sohemy A. A randomized trial of genetic information for personalized nutrition. Genes Nutr. 2012;7(4):559-66. https://doi.org/10.1007/s12263-012-0290-x.

13. Maher B. Nature readers flirt with personal genomics. Nature. 2011;478(7367):19. https://doi.org/10.1038/478019a.

14. Bloss CS, Schork NJ, Topol EJ. Effect of direct-to-consumer genomewide profiling to assess disease risk. N Engl J Med. 2011;364(6):524-34. https://doi.org/10.1056/NEJMoa1011893.

15. Brolin RE, LaMarca LB, Kenler HA, et al. Malabsorptive gastric bypass in patients with superobesity. J Gastrointest Surg. 2002;6(2):195-203. discussion 4-5

16. Berger JR. The neurological complications of bariatric surgery. Arch Neurol. 2004;61(8):1185-9. https://doi.org/10.1001/ archneur.61.8.1185.

17. Shenkin A. Micronutrients in health and disease. Postgrad Med J. 2006;82(971):559-67. https://doi.org/10.1136/pgmj.2006. 047670 .

18. Geissler C, Powers H. Fundamentals of human nutrition E-book: for students and practitioners in health sciences: Churchill Livingstone Elsevier; 2009. 324 p.

19. Reddy VS, Palika R, Ismail A, et al. Nutrigenomics: Opportunities $\&$ challenges for public health nutrition. Indian J Med Res. 2018;148(5):632-41. https://doi.org/10.4103/ijmrIJMR_1738 18.

20. Lister Hill National Center for Biomedical Communications. Genetics home reference [unspecified]. Bethesda, MD: National Library of Medicine, National Institutes of Health,; 2003. Available from: http://ghr.nlm.nih.gov/.

21. Sharp P, Srai SK. Molecular mechanisms involved in intestinal iron absorption. World J Gastroenterol. 2007;13(35):4716-24. https://doi.org/10.3748/wjg.v13.i35.4716.

22. Kluijtmans LA, van den Heuvel LP, Boers GH, et al. Molecular genetic analysis in mild hyperhomocysteinemia: a common mutation in the methylenetetrahydrofolate reductase gene is a genetic risk factor for cardiovascular disease. Am J Hum Genet. 1996;58(1):35-41.

23. Borel P, Desmarchelier C. Bioavailability of fat-soluble vitamins and phytochemicals in humans: effects of genetic variation. Annu Rev Nutr. 2018;38:69-96. https://doi.org/10.1146/annurev-nutr082117-051628.

24. Dib MJ, Elliott R, Ahmadi KR. A critical evaluation of results from genome-wide association studies of micronutrient status and their utility in the practice of precision nutrition. Br J Nutr. 2019;122(2):121-30. https://doi.org/10.1017/ S0007114519001119.

25. Desmarchelier C, Borel P, Goncalves A, et al. A combination of single-nucleotide polymorphisms is associated with interindividual variability in cholecalciferol bioavailability in healthy men. J Nutr. 2016;146(12):2421-8. https://doi.org/10. 3945/jn.116.237115.

26. Nissen J, Rasmussen LB, Ravn-Haren G, et al. Common variants in CYP2R1 and GC genes predict vitamin D concentrations in healthy Danish children and adults. PLoS One. 2014;9(2): e89907. https://doi.org/10.1371/journal.pone.0089907.

27. Barry EL, Rees JR, Peacock JL, et al. Genetic variants in CYP2R1, CYP24A1, and VDR modify the efficacy of vitamin D3 supplementation for increasing serum 25-hydroxyvitamin D levels in a randomized controlled trial. J Clin Endocrinol Metab. 2014;99(10):E2133-7. https://doi.org/10.1210/jc.2014-1389.

28. NIH. Genetics Home Reference [cited 2019]. Available from: https://ghr.nlm.nih.gov/.

29. Surendran S, Adaikalakoteswari A, Saravanan P, et al. An update on vitamin B12-related gene polymorphisms and B12 status. Genes Nutr. 2018;13:2. Epub 2018/02/06. https://doi.org/10. 1186/s12263-018-0591-9.

30. Zinck JW, de Groh M, MacFarlane AJ. Genetic modifiers of folate, vitamin B-12, and homocysteine status in a cross-sectional study of the Canadian population. Am J Clin Nutr. 2015;101(6): 1295-304. Epub 2015/05/06. https://doi.org/10.3945/ajcn.115. 107219.

31. Hazra A, Kraft P, Selhub J, et al. Common variants of FUT2 are associated with plasma vitamin B12 levels. Nat Genet. 2008;40(10):1160-2. https://doi.org/10.1038/ng.210.

32. Tanaka T, Scheet P, Giusti B, et al. Genome-wide association study of vitamin B6, vitamin B12, folate, and homocysteine blood concentrations. Am J Hum Genet. 2009;84(4):477-82. https://doi. org/10.1016/j.ajhg.2009.02.011.

33. Frosst $\mathrm{P}, \mathrm{Blom} \mathrm{HJ}$, Milos R, et al. A candidate genetic risk factor for vascular disease: a common mutation in methylenetetrahydrofolate reductase. Nat Genet. 1995;10(1):111-3. Epub 1995/05/01. https://doi.org/10.1038/ng0595-111.

34. Bagley PJ, Selhub J. A common mutation in the methylenetetrahydrofolate reductase gene is associated with an accumulation of formylated tetrahydrofolates in red blood cells. Proc Natl Acad Sci U S A. 1998;95(22):13217-20. https://doi.org/10.1073/pnas.95. 22.13217.

35. Zhang K, Huentelman MJ, Rao F, et al. Genetic implication of a novel thiamine transporter in human hypertension. J Am Coll Cardiol. 2014;63(15):1542-55. Epub 2014/02/05. https://doi.org/ 10.1016/j.jacc.2014.01.007.

36. Mikstiene V, Songailiene J, Byckova J, et al. Thiamine responsive megaloblastic anemia syndrome: a novel homozygous SLC19A2 gene mutation identified. Am J Med Genet A. 2015;167(7):16059. Epub 2015/02/23. https://doi.org/10.1002/ajmg.a.37015.

37. Pichler I, Minelli C, Sanna S, et al. Identification of a common variant in the TFR2 gene implicated in the physiological regulation of serum iron levels. Hum Mol Genet. 2011;20(6):1232-40. https://doi.org/10.1093/hmg/ddq552.

38. Blanco-Rojo R, Baeza-Richer C, López-Parra AM, et al. Four variants in transferrin and HFE genes as potential markers of iron deficiency anaemia risk: an association study in menstruating women. Nutr Metab (Lond). 2011;8:69. https://doi.org/10.1186/ 1743-7075-8-69.

39. Gemmel K, Santry HP, Prachand VN, et al. Vitamin D deficiency in preoperative bariatric surgery patients. Surg Obes Relat Dis. 2009;5(1):54-9. https://doi.org/10.1016/j.soard.2008.07.008.

40. Bischoff-Ferrari HA, Willett WC, Wong JB, et al. Fracture prevention with vitamin $\mathrm{D}$ supplementation: a meta-analysis of randomized controlled trials. JAMA. 2005;293(18):2257-64. https:// doi.org/10.1001/jama.293.18.2257.

41. Holick MF. High prevalence of vitamin D inadequacy and implications for health. Mayo Clin Proc. 2006;81(3):353-73. https:// doi.org/10.4065/81.3.353. 
42. Chakhtoura MT, Nakhoul NN, Shawwa K, et al. Hypovitaminosis $\mathrm{D}$ in bariatric surgery: A systematic review of observational studies. Metabolism. 2016;65(4):574-85. https://doi.org/10.1016/j. metabol.2015.12.004.

43. Peterson LA, Zeng X, Caufield-Noll CP, et al. Vitamin D status and supplementation before and after bariatric surgery: a comprehensive literature review. Surg Obes Relat Dis. 2016;12(3):693702. https://doi.org/10.1016/j.soard.2016.01.001.

44. Afzal S, Brøndum-Jacobsen P, Bojesen SE, et al. Genetically low vitamin D concentrations and increased mortality: Mendelian randomisation analysis in three large cohorts. BMJ. 2014;349: g6330. https://doi.org/10.1136/bmj.g6330.

45. Shea MK, Benjamin EJ, Dupuis J, et al. Genetic and non-genetic correlates of vitamins K and D. Eur J Clin Nutr. 2009;63(4):458 64. https://doi.org/10.1038/sj.ejen.1602959.

46. Waterhouse M, Tran B, Armstrong BK, et al. Environmental, personal, and genetic determinants of response to vitamin D supplementation in older adults. J Clin Endocrinol Metab. 2014;99(7):E1332-40. https://doi.org/10.1210/jc.2013-4101.

47. Didriksen A, Grimnes G, Hutchinson MS, et al. The serum 25hydroxyvitamin $\mathrm{D}$ response to vitamin $\mathrm{D}$ supplementation is related to genetic factors, BMI, and baseline levels. Eur J Endocrinol. 2013;169(5):559-67. https://doi.org/10.1530/EJE-13-0233.

48. Quinlivan EP, McPartlin J, McNulty H, et al. Importance of both folic acid and vitamin B12 in reduction of risk of vascular disease. Lancet. 2002;359(9302):227-8. https://doi.org/10.1016/s01406736(02)07439-1.

49. Hin H, Clarke R, Sherliker P, et al. Clinical relevance of low serum vitamin B12 concentrations in older people: the Banbury B12 study. Age Ageing. 2006;35(4):416-22. https://doi.org/10.1093/ ageing/afl033.

50. O'Leary F, Samman S. Vitamin B12 in health and disease. Nutrients. 2010;2(3):299-316. https://doi.org/10.3390/ nu2030299.

51. Lechner K, Födinger M, Grisold W, et al. Vitamin B12 deficiency. New data on an old theme. Wien Klin Wochenschr. 2005;117(17): 579-91. https://doi.org/10.1007/s00508-005-0406-z.

52. Collaboration HLT. Dose-dependent effects of folic acid on blood concentrations of homocysteine: a meta-analysis of the randomized trials. Am J Clin Nutr. 2005;82(4):806-12. https://doi.org/10. 1093/ajen/82.4.806.

53. Spence JD, Bang H, Chambless LE, et al. Vitamin intervention for stroke prevention trial: an efficacy analysis. Stroke. 2005;36(11): 2404-9. https://doi.org/10.1161/01.STR.0000185929.38534.f3.

54. Arendt JF, Nexo E. Unexpected high plasma cobalamin: proposal for a diagnostic strategy. Clin Chem Lab Med. 2013;51(3):48996. https://doi.org/10.1515/cclm-2012-0545.

55. Arendt JF, Pedersen L, Nexo E, et al. Elevated plasma vitamin B12 levels as a marker for cancer: a population-based cohort study. J Natl Cancer Inst. 2013;105(23):1799-805. https://doi. org/10.1093/jnci/djt315.

56. Stabler SP. Vitamin B12 deficiency. N Engl J Med. 2013;368(21): 2041-2. https://doi.org/10.1056/NEJMc1304350.

57. Flancbaum L, Belsley S, Drake V, et al. Preoperative nutritional status of patients undergoing Roux-en-Y gastric bypass for morbid obesity. J Gastrointest Surg. 2006;10(7):1033-7. https://doi.org/ 10.1016/j.gassur.2006.03.004.

58. Mehaffey JH, Mehaffey RL, Mullen MG, et al. Nutrient deficiency 10 years following Roux-en-Y gastric bypass: who's responsible? Obes Surg. 2017;27(5):1131-6. https://doi.org/10.1007/ s11695-016-2364-0.

59. Skroubis G, Sakellaropoulos G, Pouggouras K, et al. Comparison of nutritional deficiencies after Roux-en-Y gastric bypass and after biliopancreatic diversion with Roux-en-Y gastric bypass. Obes Surg. 2002;12(4):551-8. https://doi.org/10.1381/096089202762252334.
60. Vargas-Ruiz AG, Hernández-Rivera G, Herrera MF. Prevalence of iron, folate, and vitamin B12 deficiency anemia after laparoscopic Roux-en-Y gastric bypass. Obes Surg. 2008;18(3):288-93. https://doi.org/10.1007/s11695-007-9310-0.

61. Quadros EV. Advances in the understanding of cobalamin assimilation and metabolism. Br J Haematol. 2010;148(2):195-204. Epub 2009/10/12. https://doi.org/10.1111/j.1365-2141.2009.07937.x.

62. Li N, Rosenblatt DS, Kamen BA, et al. Identification of two mutant alleles of transcobalamin II in an affected family. Hum Mol Genet. 1994;3(10):1835-40. https://doi.org/10.1093/hmg/3.10.1835.

63. Coelho D, Suormala T, Stucki M, et al. Gene identification for the cblD defect of vitamin B12 metabolism. N Engl J Med. 2008;358(14):1454-64. https://doi.org/10.1056/NEJMoa072200.

64. Nilsson SE, Read S, Berg S, et al. Heritabilities for fifteen routine biochemical values: findings in 215 Swedish twin pairs 82 years of age or older. Scand J Clin Lab Invest. 2009;69(5):562-9. https://doi.org/10.1080/00365510902814646.

65. Grarup N, Sulem P, Sandholt CH, et al. Genetic architecture of vitamin B12 and folate levels uncovered applying deeply sequenced large datasets. PLoS Genet. 2013;9(6):e1003530. Epub 2013/06/06. https://doi.org/10.1371/journal.pgen.1003530.

66. Johnston J, Bollekens J, Allen RH, et al. Structure of the cDNA encoding transcobalamin I, a neutrophil granule protein. J Biol Chem. 1989;264(27):15754-7.

67. Stanisławska-Sachadyn A, Woodside JV, Sayers CM, et al. The transcobalamin (TCN2) 776C $>$ G polymorphism affects homocysteine concentrations among subjects with low vitamin $\mathrm{B}(12)$ status. Eur J Clin Nutr. 2010;64(11):1338-43. Epub 2010/09/01. https://doi.org/10.1038/ejen.2010.157.

68. Andrew T, Gill R, Gillham-Nasenya I, et al. Unravelling the basis of variability in cobalamin levels in the general population. Br J Nutr. 2013;110(9):1672-9. Epub 2013/04/29. https://doi.org/10. 1017/S0007114513000974.

69. Matteini AM, Walston JD, Bandeen-Roche K, et al. Transcobalamin-II variants, decreased vitamin B12 availability and increased risk of frailty. J Nutr Health Aging. 2010;14(1): 73-7. https://doi.org/10.1007/s12603-010-0013-1.

70. Nazki FH, Sameer AS, Ganaie BA. Folate: metabolism, genes, polymorphisms and the associated diseases. Gene. 2014;533(1):11-20. Epub 2013/10/01. https://doi.org/10.1016/j.gene.2013.09.063.

71. Bailey LB, Gregory JF. Folate metabolism and requirements. J Nutr. 1999;129(4):779-82. https://doi.org/10.1093/jn/129.4.779.

72. Hubner RA, Houlston RS. Folate and colorectal cancer prevention. Br J Cancer. 2009;100(2):233-9. Epub 2008/12/16. doi: https://doi.org/10.1038/sj.bjc.6604823.

73. Blom HJ, Smulders Y. Overview of homocysteine and folate metabolism. With special references to cardiovascular disease and neural tube defects. J Inherit Metab Dis. 2011;34(1):75-81. Epub 2010/09/04. https://doi.org/10.1007/s10545-010-9177-4.

74. Smithells RW, Sheppard S, Schorah CJ. Vitamin deficiencies and neural tube defects. Arch Dis Child. 1976;51(12):944-50. https:// doi.org/10.1136/adc.51.12.944.

75. Prevention of neural tube defects: results of the Medical Research Council Vitamin Study. MRC Vitamin Study Research Group. Lancet. 1991;338(8760):131-7.

76. Komorniak N, Szczuko M, Kowalewski B, et al. Nutritional deficiencies, bariatric surgery, and serum homocysteine level: review of current literature. Obes Surg. 2019;29(11):3735-42. https://doi. org/10.1007/s11695-019-04100-2.

77. Eldibany MM, Caprini JA. Hyperhomocysteinemia and thrombosis: an overview. Arch Pathol Lab Med. 2007;131(6):872-84. https://doi. org/10.1043/1543-2165(2007)131[872:HATAO]2.0.CO;2.

78. Clarke R, Halsey J, Lewington S, et al. Effects of lowering homocysteine levels with B vitamins on cardiovascular disease, cancer, and cause-specific mortality: meta-analysis of 8 randomized trials 
involving 37485 individuals. Arch Intern Med. 2010;170(18): 1622-31. https://doi.org/10.1001/archinternmed.2010.348.

79. Xanthakos SA. Nutritional deficiencies in obesity and after bariatric surgery. Pediatr Clin N Am. 2009;56(5):1105-21. https://doi. org/10.1016/j.pcl.2009.07.002.

80. de Luis DA, Pacheco D, Izaola O, et al. Clinical results and nutritional consequences of biliopancreatic diversion: three years of follow-up. Ann Nutr Metab. 2008;53(3-4):234-9. Epub 2008/12/16. https://doi.org/10.1159/000185641.

81. Mallory GN, Macgregor AM. Folate status following gastric bypass surgery (the great Folate mystery). Obes Surg. 1991;1(1):69 72. https://doi.org/10.1381/096089291765561493.

82. Toh SY, Zarshenas N, Jorgensen J. Prevalence of nutrient deficiencies in bariatric patients. Nutrition. 2009;25(11-12):1150-6. Epub 2009/05/31. https://doi.org/10.1016/j.nut.2009.03.012.

83. Bal BS, Finelli FC, Shope TR, et al. Nutritional deficiencies after bariatric surgery. Nat Rev Endocrinol. 2012;8(9):544-56. Epub 2012/04/24. https://doi.org/10.1038/nrendo.2012.48.

84. Gudzune KA, Huizinga MM, Chang HY, et al. Screening and diagnosis of micronutrient deficiencies before and after bariatric surgery. Obes Surg. 2013;23(10):1581-9. https://doi.org/10.1007/ s11695-013-0919-x.

85. Wilcken B, Bamforth F, Li Z, et al. Geographical and ethnic variation of the $677 \mathrm{C}>\mathrm{T}$ allele of 5,10 methylenetetrahydrofolate reductase (MTHFR): findings from over 7000 newborns from 16 areas world wide. J Med Genet. 2003;40(8):619-25. https://doi. org/10.1136/jmg.40.8.619.

86. Hiraoka M, Kagawa Y. Genetic polymorphisms and folate status. Congenit Anom (Kyoto). 2017;57(5):142-9. Epub 2017/07/20. https://doi.org/10.1111/cga.12232.

87. Steluti J, Carvalho AM, Carioca AAF, et al. Genetic variants involved in one-carbon metabolism: polymorphism frequencies and differences in homocysteine concentrations in the folic acid fortification era. Nutrients. 2017;9(6) Epub 2017/05/25 https://doi.org/ 10.3390/nu9060539.

88. Schneider JA, Rees DC, Liu YT, et al. Worldwide distribution of a common methylenetetrahydrofolate reductase mutation. Am J Hum Genet. 1998;62(5):1258-60. https://doi.org/10.1086/301836.

89. Botto LD, Yang Q. 5,10-Methylenetetrahydrofolate reductase gene variants and congenital anomalies: a HuGE review. Am J Epidemiol. 2000;151(9):862-77. https://doi.org/10.1093/ oxfordjournals.aje.a010290.

90. Guerrini I, Thomson AD, Cook CC, et al. Direct genomic PCR sequencing of the high affinity thiamine transporter (SLC19A2) gene identifies three genetic variants in Wernicke Korsakoff syndrome (WKS). Am J Med Genet B Neuropsychiatr Genet. 2005;137B(1):17-9. https://doi.org/10.1002/ajmg.b.30194.

91. Zhao R, Goldman ID. Folate and thiamine transporters mediated by facilitative carriers (SLC19A1-3 and SLC46A1) and folate receptors. Mol Asp Med. 2013;34(2-3):373-85. https://doi.org/ 10.1016/j.mam.2012.07.006.

92. Frank RA, Leeper FJ, Luisi BF. Structure, mechanism and catalytic duality of thiamine-dependent enzymes. Cell Mol Life Sci. 2007;64(7-8):892-905. https://doi.org/10.1007/s00018-007-6423-5.

93. Eshak ES, Arafa AE. Thiamine deficiency and cardiovascular disorders. Nutr Metab Cardiovasc Dis. 2018;28(10):965-72. Epub 2018/06/22. https://doi.org/10.1016/j.numecd.2018.06.013.

94. Carrodeguas L, Kaidar-Person O, Szomstein S, et al. Preoperative thiamine deficiency in obese population undergoing laparoscopic bariatric surgery. Surg Obes Relat Dis. 2005;1(6):517-22; discussion 22. Epub 2005/09/28 https://doi.org/10.1016/j.soard.2005.08.003.

95. Costello E, Kerns J. Thiamine deficiency in people with obesity. Current Developments in Nutrition. June 2019;3(Supplement_1): P18-060-19.

96. Arora S, Lidor A, Abularrage CJ, et al. Thiamine (vitamin B1) improves endothelium-dependent vasodilatation in the presence of hyperglycemia. Ann Vasc Surg. 2006;20(5):653-8. Epub 2006/05/31. https://doi.org/10.1007/s10016-006-9055-6.

97. Tanaka T, Sohmiya K, Kono $\mathrm{T}$, et al. Thiamine attenuates the hypertension and metabolic abnormalities in CD36-defective SHR: uncoupling of glucose oxidation from cellular entry accompanied with enhanced protein O-GlcNAcylation in CD36 deficiency. Mol Cell Biochem. 2007;299(1-2):23-35. https://doi. org/10.1007/s11010-005-9032-3.

98. Alaei-Shahmiri F, Soares MJ, Zhao Y, et al. The impact of thiamine supplementation on blood pressure, serum lipids and C-reactive protein in individuals with hyperglycemia: a randomised, double-blind cross-over trial. Diabetes Metab Syndr. 2015;9(4):213-7. Epub 2015/04/29. https://doi.org/10.1016/j.dsx.2015.04.014.

99. Zang XL, Han WQ, Yang FP, Ji KD, Wang JG, Gao PJ, et al. Association of a SNP in SLC35F3 gene with the risk of hypertension in a Chinese Han population. Front Genet. 2016;7:108. Epub 2016/06/20. doi: https://doi.org/10.3389/fgene.2016.00108.

100. Ortigoza-Escobar JD, Molero-Luis M, Arias A, et al. Treatment of genetic defects of thiamine transport and metabolism. Expert Rev Neurother. 2016;16(7):755-63. Epub 2016/05/23. https://doi.org/ 10.1080/14737175.2016.1187562.

101. Marcé-Grau A, Martí-Sánchez L, Baide-Mairena H, et al. Genetic defects of thiamine transport and metabolism: a review of clinical phenotypes, genetics, and functional studies. J Inherit Metab Dis. 2019;42(4): 581-97. Epub 2019/06/24. https://doi.org/10.1002/jimd.12125.

102. Troadec MB, Loréal $\mathrm{O}$, Brissot $\mathrm{P}$. The interaction of iron and the genome: for better and for worse. Mutat Res. 2017;774:25-32. Epub 2017/09/14. https://doi.org/10.1016/j.mrrev.2017.09.002.

103. Aigner E, Feldman A, Datz C. Obesity as an emerging risk factor for iron deficiency. Nutrients. 2014;6(9):3587-600. Epub 2014/09/11. https://doi.org/10.3390/nu6093587.

104. Dopsaj V, Topić A, Savković M, et al. Associations of Common Variants in. Dis Markers. 2019;2019:4864370. Epub 2019/03/07. https://doi.org/10.1155/2019/4864370.

105. Sonnweber T, Ress C, Nairz M, et al. High-fat diet causes iron deficiency via hepcidin-independent reduction of duodenal iron absorption. J Nutr Biochem. 2012;23(12):1600-8. Epub 2012/03/23. https://doi.org/10.1016/j.jnutbio.2011.10.013.

106. Micozzi MS, Albanes D, Stevens RG. Relation of body size and composition to clinical biochemical and hematologic indices in US men and women. Am J Clin Nutr. 1989;50(6):1276-81. https://doi.org/10.1093/ajcn/50.6.1276.

107. Cepeda-Lopez AC, Osendarp SJ, Melse-Boonstra A, et al. Sharply higher rates of iron deficiency in obese Mexican women and children are predicted by obesity-related inflammation rather than by differences in dietary iron intake. Am J Clin Nutr. 2011;93(5):975-83. Epub 2011/03/16. https://doi.org/10.3945/ajcn.110.005439.

108. Tussing-Humphreys LM, Nemeth E, Fantuzzi G, et al. Elevated systemic hepcidin and iron depletion in obese premenopausal females. Obesity (Silver Spring). 2010;18(7):1449-56. Epub 2009/10/08. https://doi.org/10.1038/oby.2009.319.

109. Malek M, Yousefi R, Safari S, et al. Dietary intakes and biochemical parameters of morbidly obese patients prior to bariatric surgery. Obes Surg. 2019;29(6):1816-22. https://doi.org/10.1007/ s11695-019-03759-x.

110. Harju E. Empty iron stores as a significant risk factor in abdominal surgery. JPEN J Parenter Enteral Nutr. 1988;12(3):282-5. https:// doi.org/10.1177/0148607188012003282.

111. Ruz M, Carrasco F, Rojas P, et al. Heme- and nonheme-iron absorption and iron status 12 mo after sleeve gastrectomy and Roux-en-Y gastric bypass in morbidly obese women. Am J Clin Nutr. 2012;96(4):810-7. Epub 2012/09/05. https://doi.org/10.3945/ajen. 112.039255 .

112. McLaren CE, McLachlan S, Garner CP, et al. Associations between single nucleotide polymorphisms in iron-related genes and 
iron status in multiethnic populations. PLoS One. 2012;7(6): e38339. https://doi.org/10.1371/journal.pone.0038339.

113. Lee PL, Barton JC, Khaw PL, et al. Common TMPRSS6 mutations and iron, erythrocyte, and pica phenotypes in 48 women with iron deficiency or depletion. Blood Cells Mol Dis. 2012;48(2): 124-7. https://doi.org/10.1016/j.bcmd.2011.12.003.

114. De Falco L, Tortora R, Imperatore N, et al. The role of TMPRSS6 and HFE variants in iron deficiency anemia in celiac disease. Am J Hematol. 2018;93(3):383-93. Epub 2017/12/18. https://doi.org/ 10.1002/ajh.24991.

115. Poggiali E, Andreozzi F, Nava I, et al. The role of TMPRSS6 polymorphisms in iron deficiency anemia partially responsive to oral iron treatment. Am J Hematol. 2015;90(4):306-9. Epub 2015/03/02. https://doi.org/10.1002/ajh.23929.

116. Tahir S, Leijssen LG, Sherif M, et al. A novel homozygous SLC19A2 mutation in a Portuguese patient with diabetes mellitus and thiamineresponsive megaloblastic anaemia. Int $\mathrm{J}$ Pediatr Endocrinol. 2015;2015(1):6. https://doi.org/10.1186/s13633-015-0002-6.

117. Fassone E, Wedatilake Y, DeVile CJ, et al. Treatable Leigh-like encephalopathy presenting in adolescence. BMJ Case Rep. 2013;2013:200838. https://doi.org/10.1136/bcr-2013-200838.

118. Banka S, de Goede C, Yue WW, et al. Expanding the clinical and molecular spectrum of thiamine pyrophosphokinase deficiency: a treatable neurological disorder caused by TPK1 mutations. Mol Genet Metab. 2014;113(4):301-6. Epub 2014/10/05. https://doi. org/10.1016/j.ymgme.2014.09.010.

119. Al-Daghri NM, Mohammed AK, Bukhari I, et al. Efficacy of vitamin D supplementation according to vitamin D-binding protein polymorphisms. Nutrition. 2019;63-64:148-54. https://doi. org/10.1016/j.nut.2019.02.003.

120. Qin X, Li J, Cui Y, et al. MTHFR C677T and MTR A2756G polymorphisms and the homocysteine lowering efficacy of different doses of folic acid in hypertensive Chinese adults. Nutr J. 2012;11(2) https://doi.org/10.1186/1475-2891-11-2.

121. Ashfield-Watt PA, Pullin CH, Whiting JM, et al. Methylenetetrahydrofolate reductase $677 \mathrm{C} \rightarrow \mathrm{T}$ genotype modulates homocysteine responses to a folate-rich diet or a low-dose folic acid supplement: a randomized controlled trial. Am J Clin Nutr. 2002;76(1):180-6. https://doi.org/10.1093/ajcn/76.1.180.

122. Lea R, Colson N, Quinlan S, et al. The effects of vitamin supplementation and MTHFR (C677T) genotype on homocysteine-lowering and migraine disability. Pharmacogenet Genomics. 2009;19(6):4228. https://doi.org/10.1097/FPC.0b013e32832af5a3.

123. Athiyarath R, Shaktivel K, Abraham V, et al. Association of genetic variants with response to iron supplements in pregnancy. Genes Nutr. 2015;10(4):474. https://doi.org/10.1007/s12263-015-0474-2.

124. Capra AP, Ferro E, Cannavò L, et al. A child with severe irondeficiency anemia and a complex TMPRSS6 genotype. Hematology. 2017;22(9):559-64. https://doi.org/10.1080/ 10245332.2017.1317990.

125. Donkin I, Versteyhe S, Ingerslev LR, et al. Obesity and bariatric surgery drive epigenetic variation of spermatozoa in humans. Cell Metab. 2016;23(2):369-78. Epub 2015/12/06. https://doi.org/10. 1016/j.cmet.2015.11.004.

126. Barres R, Kirchner H, Rasmussen M, et al. Weight loss after gastric bypass surgery in human obesity remodels promoter methylation. Cell Rep. 2013;3(4):1020-7. Epub 2013/04/11. https:// doi.org/10.1016/j.celrep.2013.03.018.

127. Pinhel MAS, Noronha NY, Nicoletti CF, et al. Changes in global transcriptional profiling of women following obesity surgery bypass. Obes Surg. 2018;28(1):176-86. https://doi.org/10.1007/ s11695-017-2828-x.

128. Sala P, Belarmino G, Torrinhas RS, et al. Gastrointestinal transcriptomic response of metabolic vitamin B12 pathways in Roux-en-Y gastric bypass. Clin Transl Gastroenterol. 2017;8(1): e212. https://doi.org/10.1038/ctg.2016.67.
129. Nicoletti CF, Cortes-Oliveira C, Pinhel MAS, Nonino CB. Bariatric surgery and precision nutrition. Nutrients. 2017;9(9). Epub 2017/09/06. doi: https://doi.org/10.3390/nu9090974.

130. Leyvraz C, Verdumo C, Suter M, et al. Changes in gene expression profile in human subcutaneous adipose tissue during significant weight loss. Obes Facts. 2012;5(3):440-51. Epub 2012/06/ 30. https://doi.org/10.1159/000341137.

131. Bandstein M, Schultes B, Ernst B, et al. The role of FTO and vitamin $\mathrm{D}$ for the weight loss effect of Roux-en-Y gastric bypass surgery in obese patients. Obes Surg. 2015;25(11):2071-7. https:// doi.org/10.1007/s11695-015-1644-4.

132. Guest NS, Horne J, Vanderhout SM, et al. Sport nutrigenomics: personalized nutrition for athletic performance. Front Nutr. 2019;6:8. https://doi.org/10.3389/fnut.2019.00008.

133. Hesketh J, Méplan C. Transcriptomics and functional genetic polymorphisms as biomarkers of micronutrient function: focus on selenium as an exemplar. Proc Nutr Soc. 2011;70:1-9. Epub 2011/05/03. https://doi.org/10.1017/S0029665111000115.

134. Paul B, Barnes S, Demark-Wahnefried W, et al. Influences of diet and the gut microbiome on epigenetic modulation in cancer and other diseases. Clin Epigenetics. 2015;7:112. https://doi.org/10. 1186/s13148-015-0144-7.

135. Nicholson JK, Holmes E, Kinross J, et al. Host-gut microbiota metabolic interactions. Science. 2012;336(6086):1262-7. Epub 2012/06/06. https://doi.org/10.1126/science.1223813.

136. Lozupone CA, Stombaugh JI, Gordon JI, et al. Diversity, stability and resilience of the human gut microbiota. Nature. 2012;489(7415):220-30. https://doi.org/10.1038/nature11550.

137. Das P, Babaei P, Nielsen J. Metagenomic analysis of microbemediated vitamin metabolism in the human gut microbiome. BMC Genomics. 2019;20(1):208. https://doi.org/10.1186/ s12864-019-5591-7.

138. Holmes E, Kinross J, Gibson GR, et al. Therapeutic modulation of microbiota-host metabolic interactions. Sci Transl Med. 2012;4(137): 137rv6. https://doi.org/10.1126/scitranslmed.3004244.

139. van Nimwegen KJ, van Soest RA, Veltman JA, et al. Is the $\$ 1000$ genome as near as we think? A cost analysis of next-generation sequencing. Clin Chem. 2016;62(11):1458-64. Epub 2016/09/14. https://doi.org/10.1373/clinchem.2016.258632.

140. Adam MP, Ardinger HH, Pagon RA, Wallace SE, Bean LJH, Stephens K, et al. GeneReviews. 1993.

141. Marino P, Touzani R, Perrier L, et al. Cost of cancer diagnosis using next-generation sequencing targeted gene panels in routine practice: a nationwide French study. Eur J Hum Genet. 2018;26(3):314-23. https://doi.org/10.1038/s41431-017-0081-3.

142. Institute NNHGR. The cost of sequencing a human genome 2019 .

143. Vlahovich N, Hughes DC, Griffiths LR, et al. Genetic testing for exercise prescription and injury prevention: AIS-Athlome consortium-FIMS joint statement. BMC Genomics. 2017;18(Suppl 8): 818. https://doi.org/10.1186/s12864-017-4185-5.

144. Annas GJ, Elias S. 23 andMe and the FDA. N Engl J Med. 2014;370(11):985-8. Epub 2014/02/12. https://doi.org/10.1056/ NEJMp1316367.

145. Green ED, Guyer MS, Institute NHGR. Charting a course for genomic medicine from base pairs to bedside. Nature. 2011;470(7333): 204-213. doi: https://doi.org/10.1038/nature09764,

146. O'Donovan CB, Walsh MC, Gibney MJ, et al. Knowing your genes: does this impact behaviour change? Proc Nutr Soc. 2017;76(3):182-91. Epub 2017/01/20. https://doi.org/10.1017/ S0029665116002949.

Publisher's Note Springer Nature remains neutral with regard to jurisdictional claims in published maps and institutional affiliations. 